\title{
Design and Characterization of a Flexible Wideband Antenna Using Polydimethylsiloxane Composite Substrate
}

\author{
S. M. Abbas $\mathbb{D}^{1}{ }^{1}$ S. C. Desai, ${ }^{2}$ K. P. Esselle ${ }^{D},{ }^{1}$ J. L. Volakis, ${ }^{3}$ and R. M. Hashmi ${ }^{1}$ \\ ${ }^{1}$ School of Engineering, Faculty of Science and Engineering, Macquarie University, Sydney, NSW 2109, Australia \\ ${ }^{2}$ Department of Electrical and Computer Engineering, Ohio State University, Columbus, OH 43210, USA \\ ${ }^{3}$ Electrical and Computing Engineering Department, Florida International University, Miami, FL 33199, USA
}

Correspondence should be addressed to S. M. Abbas; syed.abbas@mq.edu.au

Received 29 June 2017; Revised 15 November 2017; Accepted 3 December 2017; Published 8 February 2018

Academic Editor: Ding-Bing Lin

Copyright (c) 2018 S. M. Abbas et al. This is an open access article distributed under the Creative Commons Attribution License, which permits unrestricted use, distribution, and reproduction in any medium, provided the original work is properly cited.

The design and characterization of a simple, flexible wideband antenna using polydimethylsiloxane (PDMS) composite are presented. Conductive fibers are used to construct the metallic parts on a PDMS composite. To characterize the performance, two identical antennas are designed, one using the PDMS composite while the other on conventional dielectric materials. It was observed that both antennas behave well in terms of the matched bandwidth; however, the radiation towards the broadside direction is reduced when using the PDMS composite as substrate, particularly at higher frequencies. The antenna exhibits a matched bandwidth of 59.9\%, ranging from 3.43 to $11.1 \mathrm{GHz}$. Moreover, the bending analysis carried out for different scenarios show that the wideband behavior of the antenna is well preserved and the variation reaches a maximum of $1 \%$ variation.

\section{Introduction}

Flexible antennas have recently attracted significant attention for applications in healthcare monitoring, sports, rescue, and public safety [1]. One particular characteristic highly desired in such applications is the robustness of antenna to withstand dynamic operating conditions. Traditionally, antennas are fabricated by etching metal patterns on rigid substrates [2]. But these rigid antennas are prone to permanent deformation or even breakage when exposed to stress due to bending or twisting. Flexible antennas made out of copper tape [3] and conductive ink $[4,5]$ on flexible substrates have been reported in the past. However, copper-based designs were rigid and conductive inks are not suited for long-term use due to peeling.

Several embroidered antennas and wearable sensors have already been reported in the literature using conductive fibers on textiles and polymer composite substrates [2, 6-12]. Embroidered wearable RFID tags on textile and polymer composites have also been reported [13, 14]. In [6], a $2.45 \mathrm{GHz}$ dipole antenna on a PDMS substrate using copper mesh arms has been presented, and the performance was compared to a copper wire dipole. A dual-band textile antenna on PDMS substrate is reported in [7] and is evaluated against its rigid version [15]. In [9], textile antennas were demonstrated for body-worn communications and medical sensors with comparable performance to their copper counterparts. However, bandwidth of all these designs has been limited to only narrow bands. In this paper, we characterize the performance of a wideband antenna designed on a flexible substrate. The performance is compared on the basis of the material of the substrate and the method of construction. Two antennas are constructed using the same design parameters: (1) by conventional means, using metallic meshing on dielectric substrate, and (2) by embroidering conductive fibers on a flexible composite substrate. Antenna-I is made using Rogers RO3003 with copper etching, and antenna-II is embroidered on a thin layer of fabric and placed on a PDMS composite during the curing phase. Below, Section 2 presents the antenna design and Section 3 discusses the embroidered antenna fabrication using conductive fibers on PDMS. Results are presented in Section 4.

\section{Configuration and Design of Antennas}

Figure 1 shows the geometry of the printed wideband antenna. This antenna is a monopole radiator and formed 


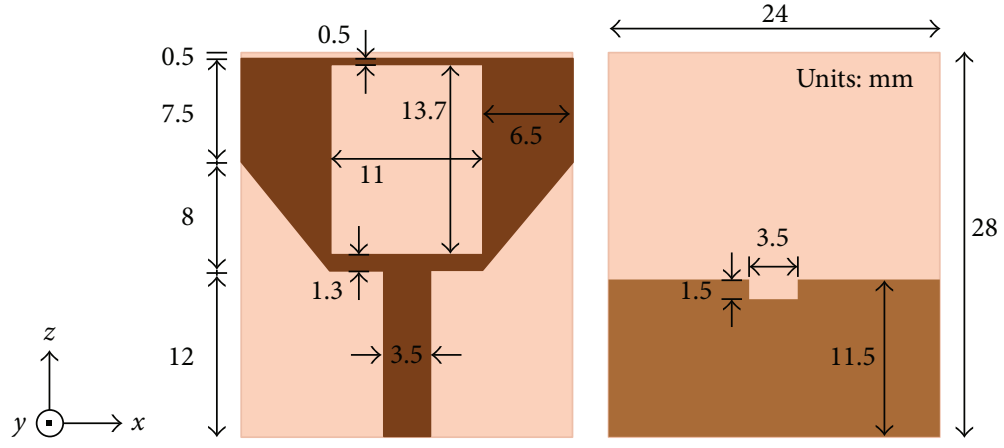

FIgURE 1: Geometry of the proposed wideband antenna.

by an extension of the microstrip line. The wideband monopole radiator is a patch with chamfered corners at the lower sides and a rectangular slot of $11 \times 13.7 \mathrm{~mm}^{2}$ in the middle. It is fed by a $50 \Omega$ microstrip line, $12 \mathrm{~mm}$ long and $3.5 \mathrm{~mm}$ wide. The partial ground plane below the microstrip line has dimensions of $11.5 \times 24 \mathrm{~mm}^{2}$ and has a slit beneath the feed line for impedance matching $[16,17]$. The antenna has overall dimensions of $24 \times 28 \mathrm{~mm}^{2}$ and covers the UWB frequency range.

The antenna in Figure 1 was designed using ANSYS High-Frequency Structural Simulator (HFSS). As will be shown, this antenna is expected to operate from 3.4311.1 GHz. Two versions of this monopole radiator were fabricated. One used copper etching on a $24 \times 28 \mathrm{~mm}^{2} \mathrm{RO} 3003$ substrate. The RO3003 substrate has a dielectric constant of $\varepsilon_{\mathrm{r}}=3$, loss tangent of $\tan \delta=0.001$, and thickness of $1.524 \mathrm{~mm}$. A textile antenna was designed, fabricated, and placed on a PDMS substrate. The PDMS composite substrate had a dielectric constant of $\varepsilon_{\mathrm{r}}=3$, loss tangent of $\tan \delta=0.01$, and thickness of $1.524 \mathrm{~mm}$. For this increased loss factor, the gain drops as frequency increases for the PDMS antenna. The gain for RO3003 antenna increases as expected since the size increases at higher frequencies while the loss factor is consistent. Moreover, the conductivity of Liberator $20^{\mathrm{TM}}$ increases with frequency, which results in ohmic losses in the antenna [18].

\section{Construction of PDMS Substrate and Flexible Antenna}

3.1. PDMS Composite Substrate Fabrication. Figure 2 shows the process used for fabricating the PDMS composite substrate $[9,19,20]$. We used Sylgard 184 (Dow Corning Corp.) PDMS and adapted the procedure described in $[19,20]$. PDMS was chosen due to its mechanical flexibility, water resistance, and inherent chemical stability [19]. It was made manually by mixing the monomer and the curing agent using a ratio of $10: 1$. The air bubbles were removed before curing and the desired substrate thickness was set to $1.524 \mathrm{~mm}$. The mixture was subsequently heated and dried using a hot plate. We endeavored to keep the substrate thickness uniform. However, due to the employed manual process, some thickness variation was inevitable.

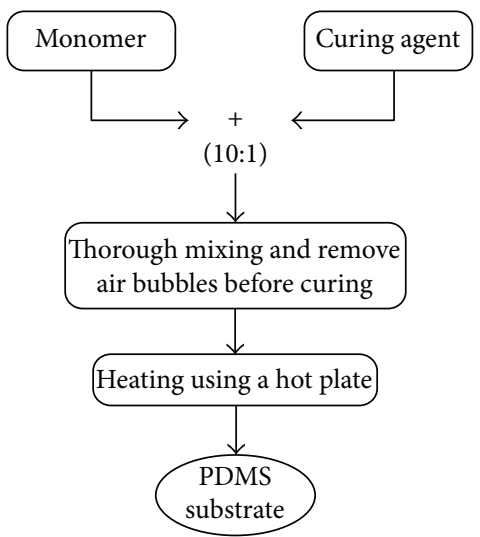

FIGURE 2: PDMS substrate fabrication process.

3.2. Antenna Construction. The antenna was constructed by embroidering on organza fabric using Liberator 20 conductive fibers. This class of conductive fibers had a DC resistance of $2 \Omega / \mathrm{ft}$. It consisted of 20 filaments, each coated with silver and bound together into a single thread. The 2-layer embroidery method described in [8] was used with a stitching density of 7 lines/mm. This 2-layer embroidery model provided far better conductivity [21]. Figure 3 shows the antenna fabrication process, starting with the simulated design model to embroider the antenna integrated with the PDMS substrate. We note that a nonstretchable support fabric was used during the embroidery process. This support fabric (organza) was later removed from the embroidered surface by dipping the entire structure into warm water to dissolve the organza. Subsequently, the embroidered parts were placed on a wet PDMS. The curing process took several hours and sealed the embroidered antenna into the polymer coating.

\section{Results and Discussion}

The and textile prototypes were measured and the corresponding reflection coefficients are given in Figure 4. It is noted that antenna-I exhibited a $10 \mathrm{~dB}$ return-loss bandwidth from 3.1-10.6 GHz. Antenna-II (textile on PDMS) had a corresponding bandwidth of $3.43-11.1 \mathrm{GHz}$. A small shift was observed in antenna-II at the lower-frequency end. This 


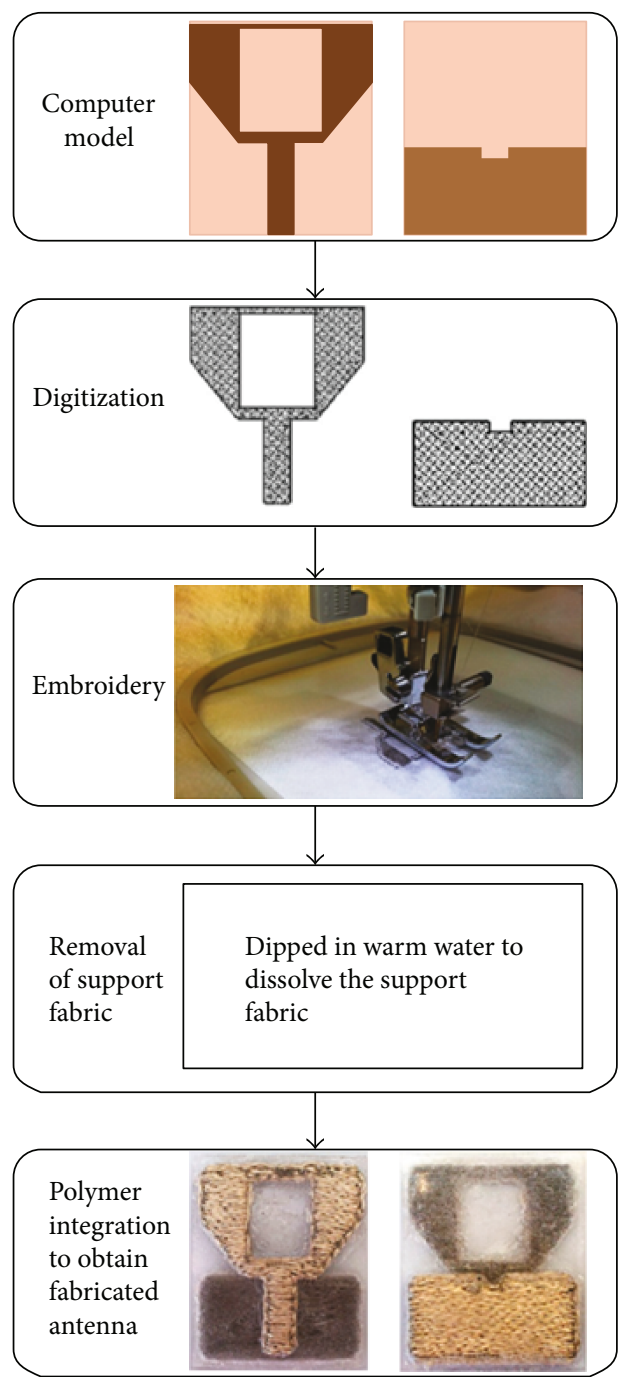

Figure 3: Process of constructing PDMS and flexible antenna structure.

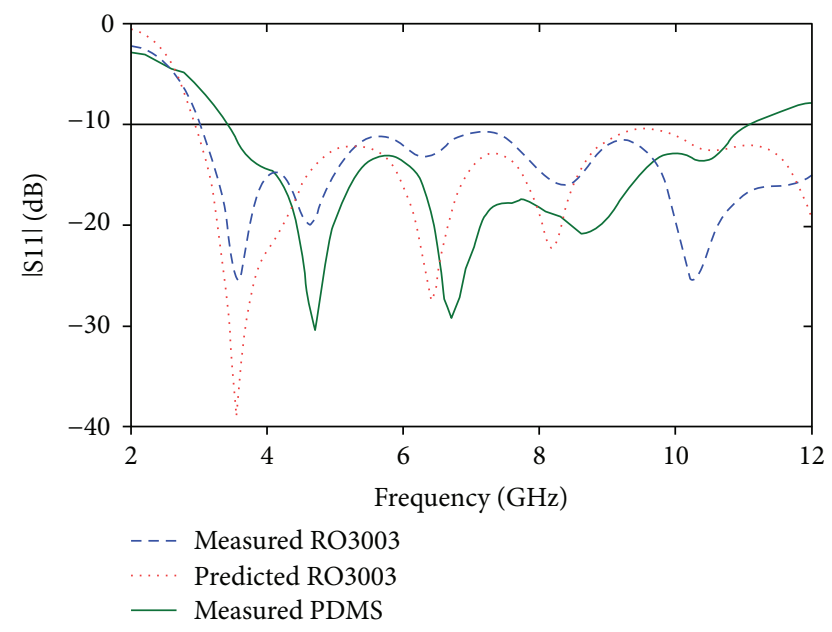

Figure 4: Measured and predicted reflection coefficients of the two antennas fabricated on Rogers and PDMS substrates.

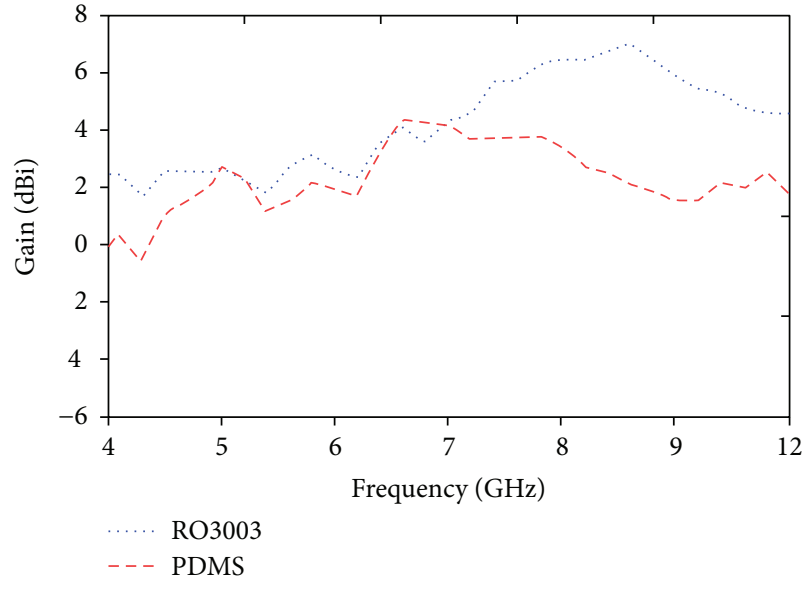

FIgURE 5: Measured broadside gain of the metallic and textile antennas fabricated on Rogers and PDMS substrates, respectively.

was caused by a slight reduction of electrical length of the antenna, since sharp edges cannot be perfectly embroidered as compared to copper etching. Furthermore, slight mismatches can also be observed at the higher-frequency end. This mismatch is caused by misalignment of the slot in the ground plane with the metallic radiating part on the top surface. The reason for misalignment was that the metallic layers were placed on the PDMS composite manually before the sealing phase. It was observed using parametric analysis that the matched bandwidth of the antenna was particularly sensitive to the placement of this slot in the ground plane. Other than the corner cases, antenna-I and antenna-II were found to demonstrate reasonably agreeable performance over the entire bandwidth.

Broadside gain of both the antennas is shown in Figure 5. It can be observed that there is a significant decrease in the gain of antenna-II at higher frequencies. This is caused due to the tilting of the main radiating lobe to off-broadside directions at higher frequencies, which can be observed in the radiation patterns in Figure 6. However, the performance of antenna-II is reasonable because the average broadside gain of the antenna is ranging between $2-4 \mathrm{dBi}$, which is often desired for such type of antennas. Moreover, at higher frequencies $(>7 \mathrm{GHz})$, the textile's losses increase leading to lower gain as compared to the metallic antenna. Measured radiation patterns for each of the antenna prototypes at 4 different frequencies are presented in Figure 6. The H-plane patterns present omnidirectional radiation and are not shown here for brevity.

Two different scenarios of bending have been considered, one along $x$-axis and the other along $z$-axis. To realize bending, a cylindrical surface with different radii is considered and the antenna is placed on the curved surface. Inset of Figures 7 and 8 presents the bending scenarios. The bandwidths corresponding to different bending radii in both scenarios are tabulated in Table 1 . The bandwidth was found to vary with the bending angles, reaching a maximum of $1 \%$ variation as shown in Figures 7 and 8. The wideband behavior, however, was found to be well preserved. 


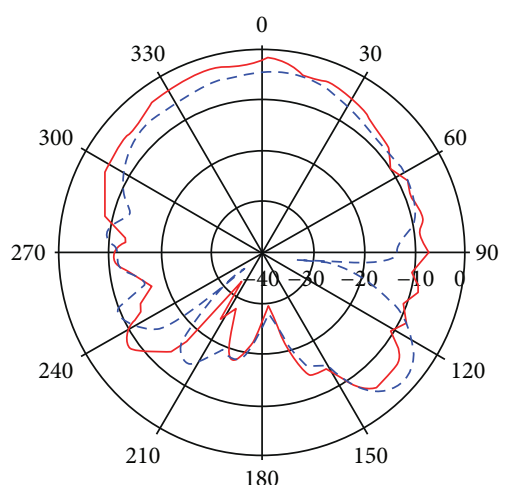

(a)

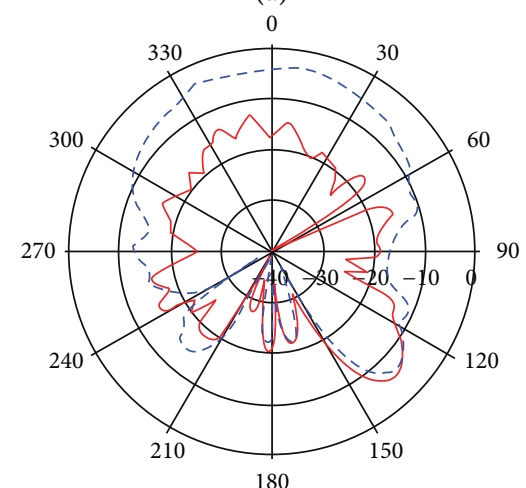

(c)

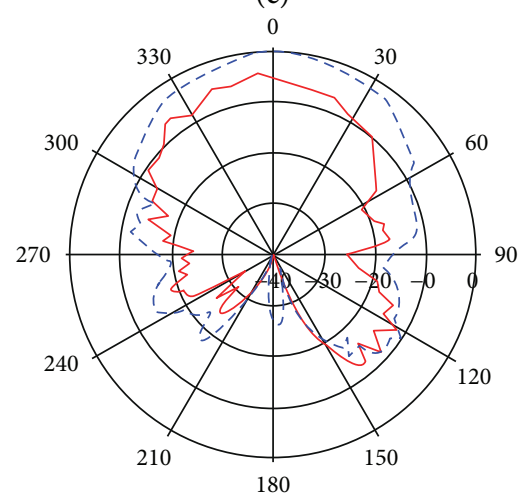

(e)

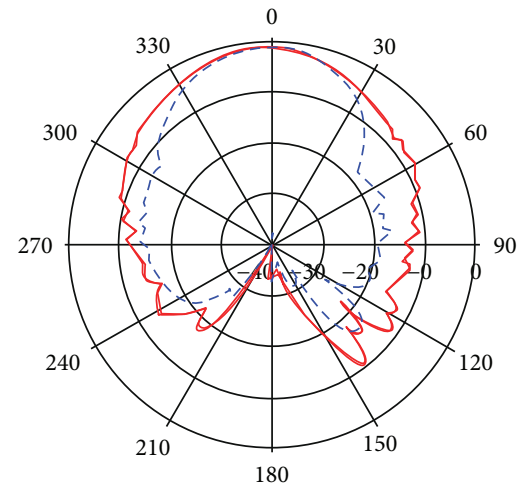

(g)

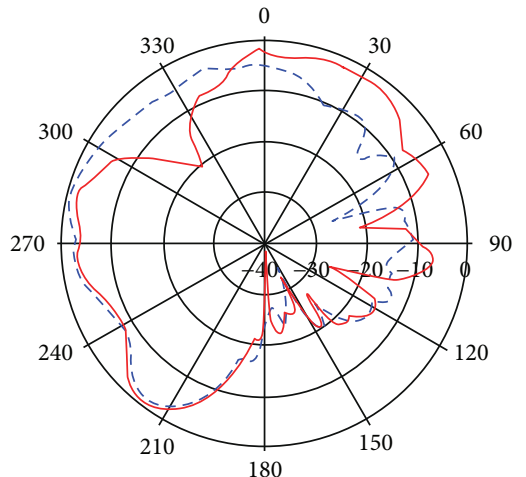

(b)

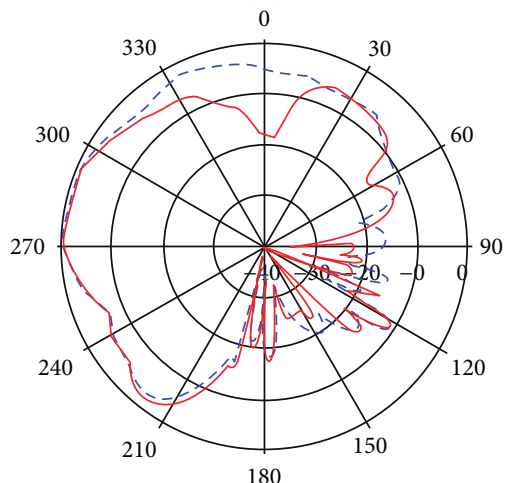

(d)

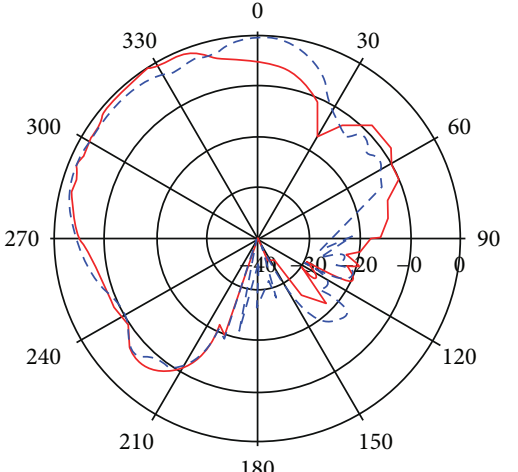

(f)

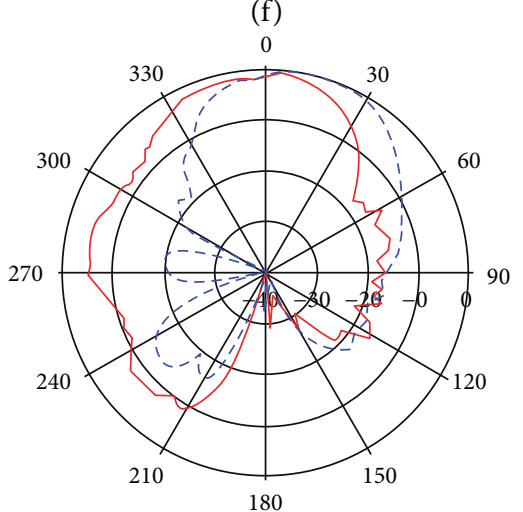

(h)

- Antenna-I (PDMS)

- - -Antenna-I (RO3003)

Figure 6: Measured radiation patterns (a) $\phi=0^{\circ}$ and (b) $\phi=90^{\circ}$ at $3.5 \mathrm{GHz}$, (c) $\phi=0^{\circ}$ and (d) $\phi=90^{\circ}$ at $5 \mathrm{GHz}$, (e) $\phi=0^{\circ}$ and (f) $\phi=90^{\circ}$ at $7 \mathrm{GHz}$, and (g) $\phi=0^{\circ}$ and $(\mathrm{h}) \phi=90^{\circ}$ at $10 \mathrm{GHz}$ for the two antennas fabricated on and PDMS substrates. 


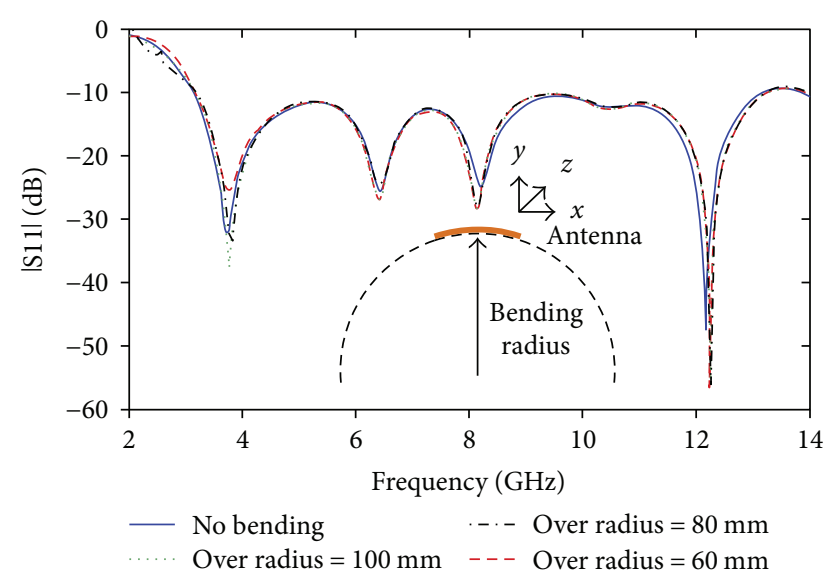

FIGURE 7: Bending results in terms of predicted reflection coefficient for textile antennas fabricated on PDMS substrates along the $x$-axis at different bending radii. Inset of the figure shows the antenna bending scenario.

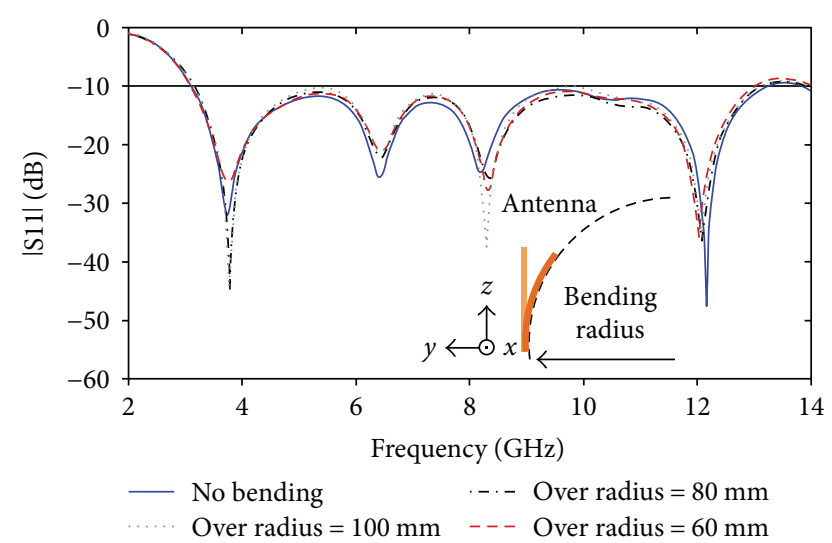

FIGURE 8: Bending results in terms of predicted reflection coefficient for textile antennas fabricated on PDMS substrates along the $z$-axis at different bending radii. Inset of the figure shows the antenna bending scenario.

TABLE 1: Bandwidths corresponding to different bending scenarios.

\begin{tabular}{lcccc}
\hline & $\begin{array}{c}\text { Bending radius } \\
(\mathrm{mm})\end{array}$ & $\begin{array}{c}f_{\mathrm{L}} \\
(\mathrm{GHz})\end{array}$ & $\begin{array}{c}f_{\mathrm{H}} \\
(\mathrm{GHz})\end{array}$ & $\begin{array}{c}\text { Bandwidth } \\
(\mathrm{GHz})\end{array}$ \\
\hline No bending & - & 3.125 & 13.24 & 10.115 \\
\hline Bending & 100 & 3.12 & 13.245 & 10.125 \\
along $x$-axis & 80 & 3.175 & 13.23 & 10.055 \\
& 60 & 3.18 & 13.33 & 10.15 \\
\hline \multirow{2}{*}{ Bending } & 100 & 3.165 & 13.075 & 9.91 \\
along $z$-axis & 80 & 3.15 & 13.16 & 10.01 \\
& 60 & 3.10 & 13.02 & 9.92 \\
\hline
\end{tabular}

\section{Conclusion}

The design and characterization of a simple, flexible wideband antenna using polydimethylsiloxane (PDMS) composite were demonstrated. It was found that antennas on PDMS composites can provide reasonable performance, in comparison to their conventional dielectric-based counterparts. The characterization was done using two identical antennas designed, one using the PDMS composite while the other on conventional dielectric materials. The antenna exhibits a matched bandwidth of 59.9\%, ranging from 3.43 to $11.1 \mathrm{GHz}$ and with the different bending angles, the variation in the bandwidth is within maximum of $1 \%$ variation.

\section{Conflicts of Interest}

The authors declare that they have no conflicts of interest.

\section{References}

[1] P. S. Hall and Y. Hao, Antennas and Propagation for BodyCentric Wireless Communications, Artech House Inc., Norwood, MA, USA, 2006.

[2] A. Kiourti and J. L. Volakis, "Stretchable and flexible E-fiber wire antennas embedded in polymer," IEEE Antennas and Wireless Propagation Letters, vol. 13, pp. 1381-1384, 2014.

[3] S. Shahid, M. Rizwan, M. A. B. Abbasi, H. Zahra, S. M. Abbas, and M. A. Tarar, "Textile antenna for body centric WiMAX and WLAN applications," in International Conference on Emerging Technologies (ICET), pp. 1-5, Islamabad, Pakistan, 2012.

[4] A. Rida, Y. Li, R. Vyas, and M. M. Tentzeris, "Conductive inkjet-printed antennas on flexible low-cost paper-based substrates for RFID and WSN applications," IEEE Antennas and Propagation Magazine, vol. 51, no. 3, pp. 13-23, 2009.

[5] P. V. Nikitin, S. Lam, and K. V. S. Rao, "Low cost silver ink RFID tag antennas," in IEEE International Symposium on Antennas and Propagation, vol. 2B, pp. 353-356, Washington, DC, USA, 2005.

[6] S. Morris, A. R. Chandran, N. Timmons, and J. Morrison, "Design and performance of a flexible and conformai PDMS dipole antenna for WBAN applications," in 46th European Microwave Conference (EuMC), pp. 84-87, London, UK, 2016.

[7] R. B. V. B. Simorangkir, Y. Yang, L. Matekovits, and K. P. Esselle, "Dual-band dual-mode textile antenna on PDMS substrate for body-centric communications," IEEE Antennas and Wireless Propagation Letters, vol. 16, pp. 677-680, 2017.

[8] W. Zheyu, Z. Lanlin, Y. Bayram, and J. L. Volakis, "Embroidered conductive fibers on polymer composite for conformal antennas," IEEE Transactions on Antennas and Propagation, vol. 60, no. 9, pp. 4141-4147, 2012.

[9] Z. Lanlin, W. Zheyu, and J. L. Volakis, "Textile antennas and sensors for body-worn applications," IEEE Antennas and Wireless Propagation Letters, vol. 11, pp. 1690-1693, 2012.

[10] S. Amendola, E. Moradi, K. Koski et al., "Design and optimization of mm-size implantable and wearable on-body antennas for biomedical systems," in 8th European Conference on Antennas and Propagation (EuCAP), pp. 520-524, The Hague, Netherlands, 2014.

[11] K. Koski, E. Moradi, A. A. Babar et al., "Durability of embroidered antennas in wireless body-centric healthcare applications," in 7th European Conference on Antennas and Propagation (EuCAP), pp. 565-569, Gothenburg, Sweden, 2013.

[12] S. E. Morris, Y. Bayram, Z. Lanlin, W. Zheyu, M. Shtein, and J. L. Volakis, "High-strength, metalized fibers for conformal 
load bearing antenna applications," IEEE Transactions on Antennas and Propagation, vol. 59, no. 9, pp. 3458-3462, 2011.

[13] S. Shuai, A. Kiourti, R. Burkholder, and J. Volakis, "Broadband and flexible textile RFID tags for tires," in IEEE International Symposium on Antennas and Propagation, pp. 1507-1507, Memphis, TN, USA, 2014.

[14] E. Moradi, K. Koski, L. Ukkonen, Y. Rahmat-Samii, T. Bjorninen, and L. Sydanheimo, "Embroidered RFID tags in body-centric communication," in International Workshop on Antenna Technology (iWAT), pp. 367-370, Karlsruhe, Germany, 2013.

[15] R. B. V. B. Simorangkir, Y. Yang, K. P. Esselle, L. Matekovits, and S. M. Abbas, "A simple dual-band dual-mode antenna for off-/on-body centric communications," in 10th European Conference on Antennas and Propagation (EuCAP), pp. 1-3, Davos, Switzerland, 2016.

[16] K. S. Ryu and A. A. Kishk, "UWB antenna with single or dual band-notches for lower WLAN band and upper WLAN band," IEEE Transactions on Antennas and Propagation, vol. 57, no. 12, pp. 3942-3950, 2009.

[17] S. M. Abbas, Y. Ranga, A. K. Verma, and K. P. Esselle, "A simple ultra wideband printed monopole antenna with high band rejection and wide radiation patterns," IEEE Transactions on Antennas and Propagation, vol. 62, no. 9, pp. 4816-4820, 2014.

[18] A. Kiourti and J. L. Volakis, "High-geometrical-accuracy embroidery process for textile antennas with fine details," IEEE Antennas and Wireless Propagation Letters, vol. 14, pp. 1474-1477, 2015.

[19] S. Koulouridis, G. Kiziltas, Z. Yijun, D. J. Hansford, and J. L. Volakis, "Polymer-ceramic composites for microwave applications: fabrication and performance assessment," IEEE Transactions on Microwave Theory and Techniques, vol. 54, no. 12, pp. 4202-4208, 2006.

[20] J. C. McDonald and G. M. Whitesides, "Poly(dimethylsiloxane) as a material for fabricating microfluidic devices," Accounts of Chemical Research, vol. 35, no. 7, pp. 491-499, 2002.

[21] Z. Lanlin, W. Zheyu, and J. L. Volakis, "Embroidered textile circuits for microwave devices," in IEEE International Symposium on Antennas and Propagation, pp. 1-2, Chicago, IL, USA, 2012. 


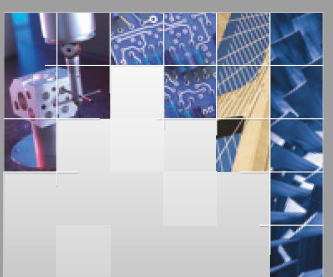

\section{Enfincering}
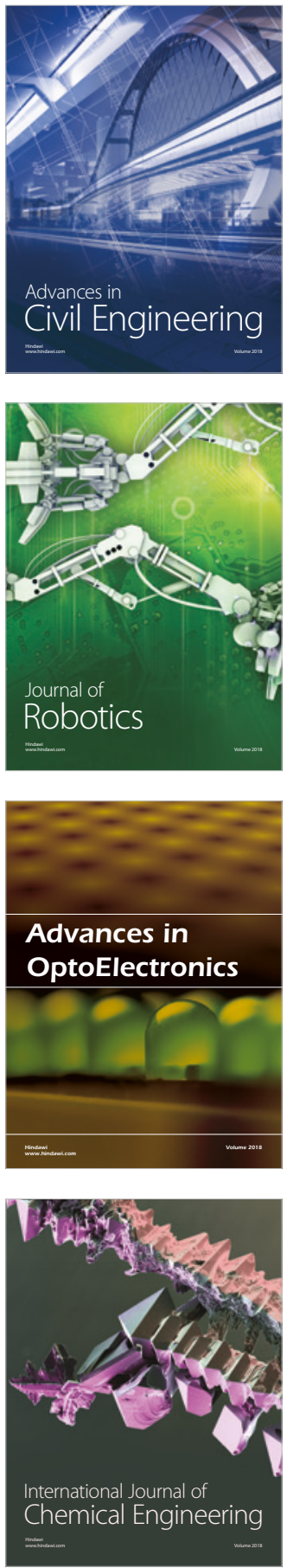

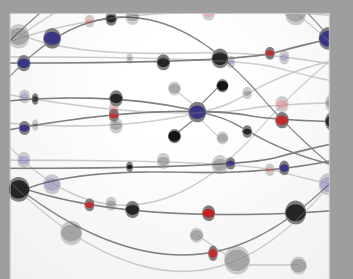

\section{Rotating \\ Machinery}

The Scientific World Journal

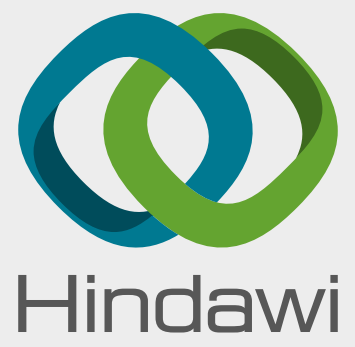

Submit your manuscripts at

www.hindawi.com
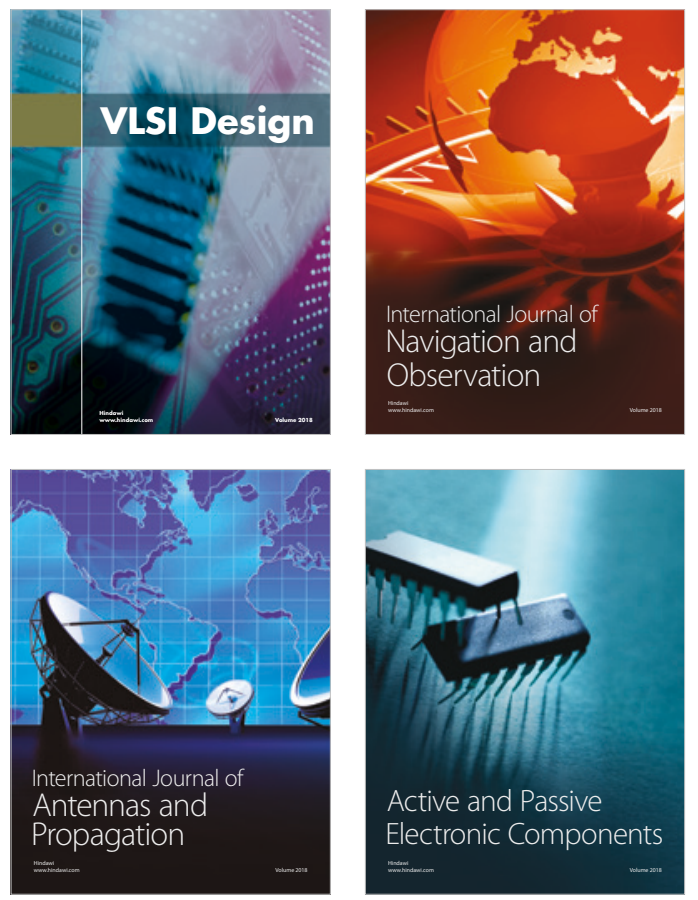
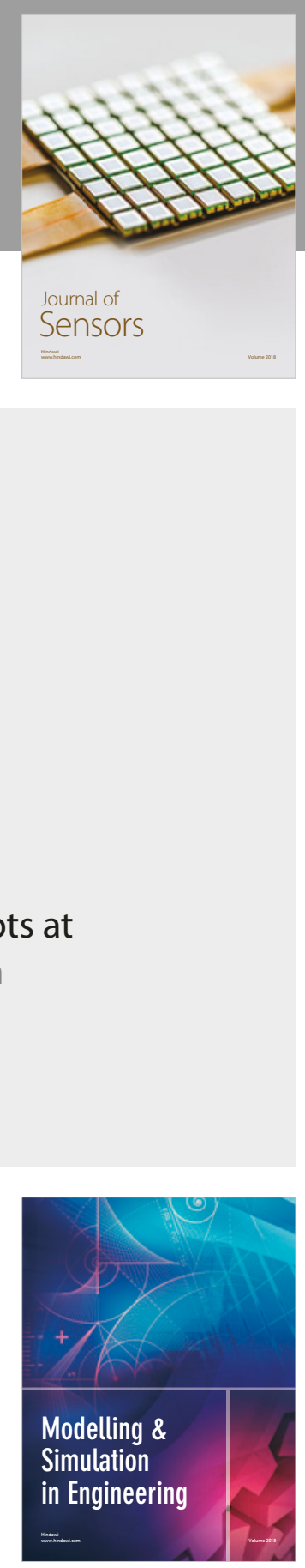

\section{Advances \\ Multimedia}
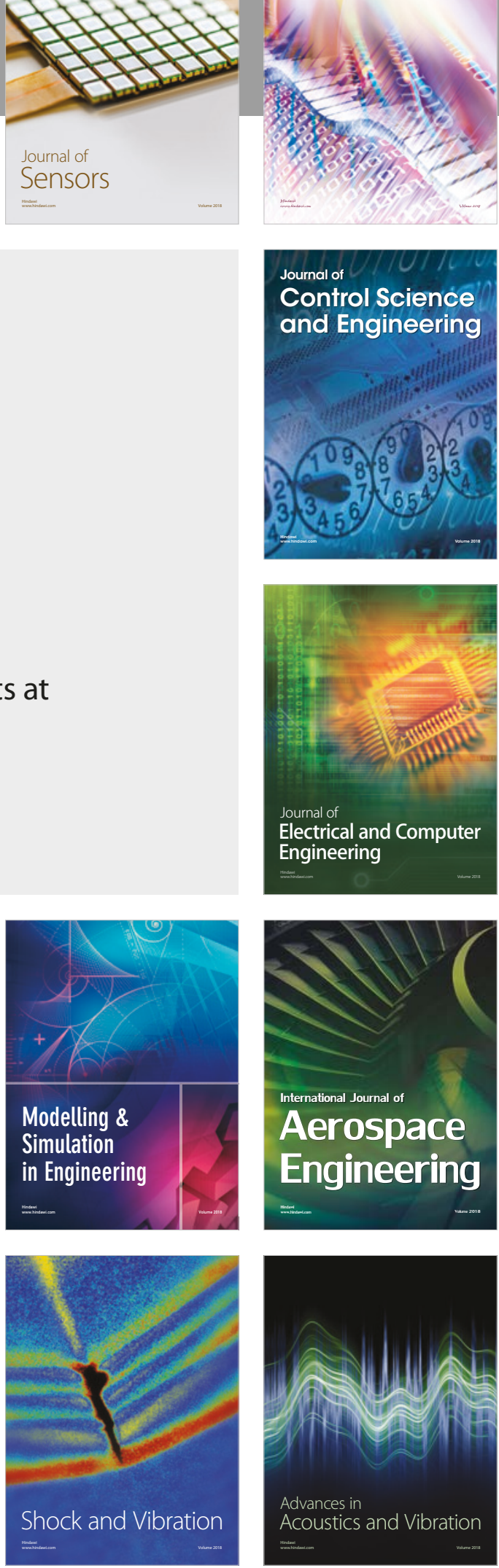